NBER WORKING PAPER SERIES

\title{
MONETARY POLICY, INTEREST RATE RULES, AND INFLATION TARGETING: SOME BASIC EQUIVALENCES
}

\author{
Carlos A. Végh
}

Working Paper 8684

http://www.nber.org/papers/w8684

\author{
NATIONAL BUREAU OF ECONOMIC RESEARCH \\ 1050 Massachusetts Avenue \\ Cambridge, MA 02138 \\ December 2001
}

This paper was prepared for a conference organized by the Central Bank of Chile on "Indexation, Inflation, and Monetary Policy" and will be published in a conference volume. I am grateful to Eduardo Borenzstein, David Gould, Esteban Jadresic, Fernando Lefort, Paul Masson, Klaus Schmidt-Hebbel, Pierre Siklos, Rajesh Singh, and seminar participants at Chile and the AEA meetings for helpful comments and discussions and to Alejandro Jara for superb research assistance. The views expressed herein are those of the author and not necessarily those of the National Bureau of Economic Research.

(C) 2001 by Carlos A. Végh. All rights reserved. Short sections of text, not to exceed two paragraphs, may be quoted without explicit permission provided that full credit, including (C) notice, is given to the source. 
Monetary Policy, Interest Rate Rules, and Inflation Targeting: Some Basic Equivalences Carlos A. Végh

NBER Working Paper No. 8684

December 2001

JEL No. E52, E58

\begin{abstract}
Policymakers increasingly view short-term nominal interest rates as the main instrument of monetary policy, often in conjunction with some inflation target. Interest rates on short-term indexed government debt (i.e., a real interest rate) have also been used as policy instruments. To understand the pros and cons of different policy rules and instruments, this paper derives some basic equivalences among different policy rules. It is shown that, under certain conditions, the following three rules are exactly equivalent: (i) a "k-percent" money growth rule; (ii) a nominal interest rate rule combined with an inflation target; and (iii) a real interest rate rule combined with an inflation target. These policy rules, however, become increasingly complex: the first rule requires no feedback mechanism; the second rule requires responding to the inflation gap; while the third rule involves responding to both the inflation gap and the output gap. It is also shown that policy rules which respond to the output gap may avoid a deflationary adjustment.
\end{abstract}

\author{
Carlos A. Végh \\ Department of Economics \\ UCLA \\ Los Angeles, CA 90095-1477 \\ and NBER \\ cvegh@ucla.edu \\ http://vegh.sscnet.ucla.edu
}




\section{Introduction}

Monetary policy in small open economies is typically cast as a choice between an exchange rate anchor (fixed or predetermined exchange rates) or a money anchor (floating exchange rates). Under such regimes, the rate of growth of the nominal anchor is set according to the desired long-run inflation rate. In response to a shock, and after undergoing a possibly costly adjustment process, the economy would eventually reach the long-run inflation rate.

In practice, however, policymakers have certainly not restricted themselves to such a limited menu of policy instruments. Pure floating rates are, at best, rare, as policymakers typically intervene in foreign exchange markets to smooth exchange rate fluctuations or achieve some international reserves target. ${ }^{1}$ While predetermined exchange rates are more common, it is still the case that, more often than not, policymakers adjust the devaluation rate in response to changes in the domestic and external environment, or engage in real exchange rate targeting. ${ }^{2}$

At an even more fundamental level, policymakers increasingly view shortterm nominal interest rates as the main nominal anchor. In developed countries, short-term interest rates are, by and large, the most common policy instrument. The most prominent example is, of course, the United States: the Federal Reserve conducts monetary policy by setting the federal funds rate (the interest rate at which commercial banks borrow overnight). When inflation raises its ugly head, the Federal Reserve engages in a gradual tightening of monetary policy by raising the federal funds rate (see, for example, Taylor (1998)).

In developing countries, short-term interest rates have also played a key role in the conduct of monetary policy. In the mid-1980's, for instance, countries such as Argentina and Brazil would support repeated stabilization attempts by hiking interest rates on short-term government debt to increase demand for domestic assets and thus prevent speculative attacks against the domestic currency (see Calvo and Végh (1995)). In the case of Mexico, analysts point to the monetary authorities' reluctance to raise interest rates as a key factor in triggering the December 1994 crisis. In the wake of Thailand's decision to abandon its fixed-exchange system in July 1997, Brazil and Hong Kong repeatedly raised interest rates to defend their currency peg and thwart

\footnotetext{
${ }^{1}$ See Calvo and Reinhart (2000) and Lahiri and Végh (2001).

${ }^{2}$ See, for instance, Bruno (1993), Calvo, Reinhart, and Végh (1995), and Lahiri (1997).
} 
currency speculators. More recently - and in response to the Argentine debt crisis - Brazil has again used higher interest rates to prevent the currency from depreciating too rapidly.

With the advent of indexed government debt, some countries - Chile being the most notable example - have actually used the interest rate on such instruments (i.e., a real interest rate) as the main policy instrument (see, for example, Corbo and Fischer (1994)). Even when policymakers do not set a real interest rate, a real interest rate target seems to be very much in their minds. Reinhart (1993), for instance, argues that the Federal Reserve may be viewed as aiming at setting a real interest rate which is consistent with full-employment output. In fact, the level of the Federal Funds rate in real terms is often an important consideration in whether to raise further interest rates or not.

In practice, the use of interest rates as the main policy instrument has often taken place in conjunction with some inflation target. In other words, policymakers set - explicitly or implicitly - an inflation target and change interest rates with the aim of achieving such a target. When inflation targets are explicitly announced, such policies have been referred to as "inflation targeting". ${ }^{3}$ Inflation targeting has been implemented in industrial countries such as New Zealand, Canada, United Kingdom, Sweden, Finland, Australia, and Spain. Although, in principle, a myriad of policy instruments could be used to achieve a given inflation target, in practice short-term interest rates have been the main policy instrument. Hence, the most common manifestation of inflation targeting appears to be an inflation target accompanied by some, explicit or implicit, interest rate rule designed so as to achieve such a target. Among developing countries, Chile is the country that seems to come the closest to using an inflationary targeting scheme (see Masson, Savastano, and Sharma (1997)).

At an analytical level, the use of nominal interest rates as a policy instrument has raised some important questions regarding its impact on prices and inflation. Nominal interest rate targeting may lead to an indeterminate price level under flexible prices (Sargent and Wallace, 1975) or indeterminate inflation rate under sticky prices (Calvo, 1983). Indeterminacy problems can be avoided by explicitly introducing a government budget constraint (Auernheimer and Contreras, 1993); by designing appropriate interest rate rules

\footnotetext{
${ }^{3}$ See, for example, Leiderman and Svensson (1995), Masson, Savastano, and Sharma (1997), Svensson (2000), and Siklos (2001)).
} 
(see, for instance, Reinhart (1992)); or by letting policymakers set the interest rate on liquid bonds issued by the government (Calvo and Végh (1995, 1996)). Policy rules which rely on real interest rates may also easily lead to various indeterminacies (Reinhart (1993)). The use of the real interest rate as a policy instrument has received particular attention in the case of Chile (see, for example, Rojas (1993), Corbo and Fischer (1994), and Mendoza and Fernandez (1994)). Although some important insights have followed from this large literature, the profession is still far from reaching any sort of consensus on the comparative advantages of different instruments and policy rules.

This paper starts from the premise that, in order to assess different policy rules, it is useful to establish some basic equivalences among policy rules. Equivalent policy rules are defined as rules which yield exactly the same dynamics in response to, say, a long-term reduction in the inflation rate. In a formal sense, finding equivalent policy rules is a trivial exercise. Consider the exercise of a permanent reduction in the rate of monetary growth in a closedeconomy model. This exercise will generate as an outcome some equilibrium path for the nominal interest rate. Clearly, if policymakers could announce a credible inflation target (which would anchor the long-run inflation rate) and set that same path for the nominal interest rate, the rate of monetary growth would endogenously fall on impact and remain at that lower level forever. These two policy rules - the fixed money-growth rule and the interest rate rule - would therefore be equivalent.

To think about the real policy world, however, this formal equivalence will be relevant only if the endogenous path of the nominal interest rate in the fixed money-growth rule is a linear function of observable variables, such as the deviation of the actual inflation rate from its long-run steady-state. In that case, an interest rate rule which sets the interest rate according to the deviation of the actual inflation rate from an inflation target would achieve the same results. Otherwise, policymakers would not be able to implement the interest rate rule which replicates the fixed money-growth rule.

This paper illustrates, in the context of a closed-economy model, the existence of some basic equivalences among policy rules (i.e., policy rules which are implementable in practice). Inflation is assumed to be a predetermined variable, reflecting the highly inertial nature of inflation in many moderate inflation countries. We first compare the use of a money anchor, a nominal interest rate anchor, and a real interest rate anchor, whereby policymakers set a fixed level of the corresponding policy instrument (that is, there is no 
feedback mechanism). It is shown that only a money anchor (i.e., a k-percent money growth rule) yields a well-behaved system. Both a fixed level of the nominal interest rate and the real interest rate lead to unstable dynamics. This first result, which is here derived for the case of sticky inflation, is thus in the spirit of the indeterminacies found in the literature. In theory, then, there is no substitute for a k-percent money rule. In practice, however, there are well-known problems associated with k-percent rules such as the instability of monetary aggregates and the choice of the appropriate monetary aggregate.

We then investigate the existence of simple interest rate rules which could replicate the k-percent money growth rule. The following rule is analyzed: let policymakers announce an inflation target and then change the nominal interest rate according to the difference between the current inflation rate and the inflation target. It is shown that, provided that the inflation target is fully credible, such a policy generates the same qualitative dynamic adjustment as the one delivered by the k-percent money rule. In fact, a simple case is found (when real money demand is of the Cagan type and thus has a constant interest rate semi-elasticity) in which the inflation target-cuminterest rate rule exactly replicates the k-percent money growth rule. In other words, the adjustment of the economy to the announcement of a lower inflation target replicates exactly the response of the economy to a lower rate of monetary expansion. We then analyze the following real interest rate rule: let policymakers announce an inflation target and change the real interest rate according to the difference between (a) the current inflation rate and the inflation target and (b) deviations of output from its full-employment level. We show that, under a constant semi-elasticity money demand, this rule also replicates the k-percent money growth rule.

Hence, these three rules - the k-percent money rule, an inflation targetcum-nominal interest rate rule, and an inflation target-cum-real interest rate rule - are identical for a Cagan money demand. However, as one moves away from the more traditional instrument (a monetary aggregate) toward less traditional ones (a nominal interest rate and then a real interest rate), the policy regime becomes more complicated as the feedback mechanisms multiply. This should prove a useful conceptual benchmark. In practice, this increased level of complexity would need to be weighted against whatever practical advantages there may exist. For instance, setting a short-term nominal interest rate may be operationally easier than setting a constant growth of the money supply. 
The three equivalent policy rules just mentioned imply an adjustment toward a lower long-run inflation rate which involves a prolonged period of "deflation" (defined as inflation falling below its long-run level during the adjustment process). This is needed for real money balances to achieve a higher steady-state level. In practice, policymakers may want to avoid this deflationary period since it essentially implies that the monetary policy stance is too tight. It is shown that policy rules which respond to the output gap may prevent this deflationary period and ensure a monotonic fall of the inflation rate towards its lower steady-state value. In fact, under certain conditions, these three policy rules deliver exactly the same outcome: (a) an inflation target combined with a money-growth rule which responds to the output gap; (b) an inflation target combined with a nominal interest rate rule which responds to both the inflation gap and the output gap; and (c) an inflation target combined with a real interest rate rule which responds to both the inflation gap and the output gap. It is still the case that the money growth rule is the simplest of the three rules. But, again, a nominal interest rate rule can achieve the same results without adding too much complexity (as the inflation gap may be easily monitored by policymakers).

A final word of caution before proceeding to the formal analysis. We view the equivalence results derived in this paper as a useful conceptual benchmark. No generality is claimed. Quite to the contrary, the whole point of the exercise is to find conditions (however strong they may be) under which different policy rules are equivalent. As is typical of applied economic theory (think, for example, of the Ricardian equivalence or the Modigliani-Miller theorem), the idea is that understanding (admittedly extreme) cases where such equivalences hold should then make it easier to understand what are the main factors in the real world that may explain deviations from such benchmarks. In this context, a model in which some basic policy equivalence results hold should hopefully provide a useful starting point to think about different monetary policy rules and instruments. Put differently, the idea is to provide a useful conceptual benchmark to think about these issues rather than to construct a model which replicates the real world.

The paper proceeds as follows. Section 2 develops the basic model. Sections 3,4 , and 5 analyze the use of the money supply, the nominal interest rate, and the real interest rate as policy instruments, respectively. Section 6 derives the first equivalence proposition. Section 7 analyzes policy rules aimed at avoiding excessively tight monetary policy and derives the second equivalence proposition. Section 8 concludes. 


\section{The model}

Consider a closed economy inhabited by a very large number of identical consumers. Agents have perfect foresight. The Fischer equation holds, so that $i_{t}=r_{t}+\pi_{t}$, where $i_{t}$ is the nominal interest rate, $r_{t}$ is the real interest rate and $\pi_{t}$ is the inflation rate.

\subsection{Consumers}

The lifetime utility of the representative consumer is given by

$$
\int_{0}^{\infty} u\left(c_{t}\right) \exp (-\beta t) d t
$$

where $c_{t}$ denotes consumption, $\beta(>0)$ is the subjective discount rate, and the function $u($.$) satisfies u^{\prime}()>$.0 and $u^{\prime \prime}()<$.0 .

Consumers hold two assets: a bond (indexed to the price level and in zero net supply in the aggregate) and money. Let $a_{t}$ denote the household's financial wealth in real terms. Hence,

$$
a_{t}=b_{t}+m_{t},
$$

where $b_{t}$ and $m_{t}$ denote the real stocks of bonds and money, respectively. The bond earns a nominal return of $i_{t}$.

In this economy, trading is a costly activity (in terms of resources). Consumers hold money in order to reduce transactions costs. Transactions costs are thus given by $v\left(m_{t}\right)$, where $v^{\prime}(m)<0$ and $v^{\prime \prime}(m)>0 .{ }^{4}$

The consumer's flow constraint is given by

$$
\dot{a}_{t}=r_{t} a_{t}+y_{t}+\tau_{t}-c_{t}-i_{t} m_{t}-v\left(m_{t}\right),
$$

where $y_{t}$ denotes output of the good and $\tau_{t}$ are lump-sum transfers from the government.

The consumer chooses $\left\{c_{t}, m_{t}\right\}$ for all $t \in[0, \infty)$ to maximize lifetime utility (1), subject to (3), for given paths of $r_{t}, y_{t}, \tau_{t}$, and $i_{t}$, and a given value of $a_{0}$. The first-order conditions for this standard optimal control program are:

\footnotetext{
${ }^{4}$ See, among others, Dornbusch and Frenkel (1973). For simplicity, we assume that the transactions technology does not depend on consumption, which implies that the derived real money demand will only depend on the nominal interest rate.
} 


$$
\begin{aligned}
u^{\prime}\left(c_{t}\right) & =\lambda_{t}, \\
-v^{\prime}\left(m_{t}\right) & =i_{t}, \\
\dot{\lambda}_{t} & =\lambda_{t}\left(\beta-r_{t}\right),
\end{aligned}
$$

where $\lambda_{t}$ is the current value multiplier associated with constraint (3). Equation (4) indicates that, at an optimum, the household equates the marginal utility of consumption to the marginal utility of wealth. Equation (6) is the law of motion of the multiplier. Condition (5) states that, at an optimum, the benefits derived from holding an additional unit of real money balances will be equal to the corresponding opportunity cost. This equation implicitly defines a money demand function:

$$
m_{t}=L\left(i_{t}\right), \quad L^{\prime}\left(i_{t}\right)=-\frac{1}{v^{\prime \prime}\left(m_{t}\right)}<0 .
$$

For further reference, notice that differentiating equation (4) with respect to time and combining it with (6) leads to the familiar Euler equation:

$$
\dot{c}_{t}=\frac{u^{\prime}\left(c_{t}\right)}{-u^{\prime \prime}\left(c_{t}\right)}\left(r_{t}-\beta\right) .
$$

Hence, if, say, the real interest rate is above the rate of time preference, today's consumption is expensive relative to "tomorrow's" and hence consumption will be increasing over time.

\subsection{Government}

The government plays no active role. It gives back to consumers as lumpsum transfers the proceeds from money creation and transactions costs. The government's constraint is thus

$$
\tau_{t}=\mu_{t} m_{t}+v\left(m_{t}\right) .
$$

The fact that $v\left(m_{t}\right)$ appears in the government's flow constraint reflects the assumption that $v\left(m_{t}\right)$ is a private cost for consumers but not a social cost. Formally, one can think of some federal agency providing (at zero cost) the transactions costs needed by consumers. The profits of this federal agency are returned to households as lump-sum transfers. This assumption is made to eliminate wealth effects associated with changes in inflation which would unnecessarily complicate the analysis. 


\subsection{Supply side}

Output is endogenous and assumed to be demand-determined; that is, $y_{t}=$ $c_{t}$. The inflation rate is assumed to be predetermined at each point in time. This formulation is meant to capture a situation in which widespread backward-looking indexation of prices and wages imparts a high degree of inertia to the inflation rate. ${ }^{5}$ The change in the inflation rate is given by

$$
\dot{\pi}_{t}=\gamma\left(\mu_{t}-\pi_{t}\right)+\alpha\left(c_{t}-\bar{y}\right)
$$

where $\bar{y}$ denotes the "full-employment" level of output. Equation (10) says that the rate of inflation will increase whenever the rate of inflation is below the rate of money growth, $\mu_{t}$, or aggregate demand exceeds full-employment output.

\subsection{Equilibrium conditions}

Since bonds are "inside money" in this economy, aggregate bond holdings must be zero:

$$
b_{t}=0 \text {. }
$$

Of course, substituting the latter and goods market equilibrium, $y_{t}=c_{t}$, into the consumer's flow constraint,(3), yields the government's budget constraint, (9), which is simply a manifestation of Walras Law.

Finally, and for further reference, note that since, by definition, $m=$ $M / P$, it follows that

$$
\dot{m}_{t}=m_{t}\left(\mu_{t}-\pi_{t}\right)
$$

\section{$3 \quad$ A fixed money growth rule}

As a benchmark, consider the case in which policymakers set the initial level and the rate of growth of the nominal money supply (denoted by $\bar{\mu}$ ). Hence, equations (10) and (12) become:

$$
\dot{\pi}_{t}=\gamma\left(\bar{\mu}-\pi_{t}\right)+\alpha\left(c_{t}-\bar{y}\right),
$$

\footnotetext{
${ }^{5}$ Widespread indexation has long characterized chronic inflation countries; see, for instance, Dornbusch and Simonsen (1987), Edwards (1991), and Bruno (1993).
} 


$$
\dot{m}_{t}=m_{t}\left(\bar{\mu}-\pi_{t}\right) .
$$

Substituting into equation (8) the Fisher equation and equation (5), we obtain:

$$
\dot{c}_{t}=\frac{u^{\prime}\left(c_{t}\right)}{u^{\prime \prime}\left(c_{t}\right)}\left[\beta+v^{\prime}\left(m_{t}\right)+\pi_{t}\right] .
$$

Equations (13), (14), and (15) constitute a differential equation system in $\pi_{t}, m_{t}$, and $c_{t}$, for a given value of the policy variable $\bar{\mu}$. Both $\pi_{t}$ and $m_{t}$ are predetermined variables.

The system's steady-state is given by

$$
\begin{aligned}
\pi_{s s} & =\bar{\mu} \\
c_{s s} & =\bar{y} \\
-v^{\prime}\left(m_{s s}\right) & =\beta+\bar{\mu} .
\end{aligned}
$$

Linearizing this system around the steady-state, we obtain:

$$
\left[\begin{array}{l}
\dot{\pi}_{t} \\
\dot{m}_{t} \\
\dot{c}_{t}
\end{array}\right]=\left[\begin{array}{lll}
-\gamma & 0 & \alpha \\
-m_{s s} & 0 & 0 \\
\frac{u^{\prime}(\bar{y})}{u^{\prime \prime}(\bar{y})} & \frac{u^{\prime}(\bar{y}) v^{\prime \prime}\left(m_{s s}\right)}{u^{\prime \prime}(\bar{y})} & 0
\end{array}\right]\left[\begin{array}{l}
\pi_{t}-\bar{\mu} \\
m_{t}-m_{s s} \\
c_{t}-\bar{y}
\end{array}\right] .
$$

The trace and determinant of the matrix associated with the linear approximation are, respectively,

$$
\begin{aligned}
\operatorname{Tr} & =-\gamma<0, \\
\Delta & =-\alpha m_{s s} \frac{u^{\prime}(\bar{y}) v^{\prime \prime}\left(m_{s s}\right)}{u^{\prime \prime}(\bar{y})}>0,
\end{aligned}
$$

which implies that there is one positive root and two roots with negative real part. ${ }^{6}$ Since there are two predetermined variables, the system exhibits

\footnotetext{
${ }^{6}$ In what follows, and to simplify the exposition, it will be assumed that the roots with negative real part are real numbers. It can be checked that roots will be real (complex) numbers when $\gamma$ is large (small) relative to $\alpha$. This makes intuitive sense since, as can be seen from (13), a relatively large $\gamma$ ensures that the rate of change of the inflation rate is relative more responsive to the inflation rate differential.
} 
saddle-path stability: for given initial values of $\pi$ and $m, c$ will adjust so as to position the system along its unique perfect foresight equilibrium path.

Let $\delta_{i}, i=1,2$, denote the two negative roots, with $\delta_{1}>\delta_{2}$. Let $h_{i j}$, $j=1,2,3$, denote the elements of the eigenvector associated with root $\delta_{i}$. Hence, for $i=1,2$, it follows that

$$
\left[\begin{array}{lll}
-\gamma-\delta_{i} & 0 & \alpha \\
-m_{s s} & -\delta_{i} & 0 \\
\frac{u^{\prime}(\bar{y})}{u^{\prime \prime}(\bar{y})} & \frac{u^{\prime}(\bar{y}) v^{\prime \prime}\left(m_{s s}\right)}{u^{\prime \prime}(\bar{y})} & -\delta_{i}
\end{array}\right]\left[\begin{array}{l}
h_{i 1} \\
h_{i 2} \\
h_{i 3}
\end{array}\right]=\left[\begin{array}{l}
0 \\
0 \\
0
\end{array}\right]
$$

Therefore,

$$
\frac{h_{i 1}}{h_{i 2}}=-\frac{\delta_{i}}{m_{s s}}>0 .
$$

As will become clear below, this will provide a crucial piece of information when it comes to deriving the dynamic behavior of the system.

Setting to zero the constant corresponding to the unstable root, the solution to this dynamic system takes the form:

$$
\begin{aligned}
\pi_{t}-\bar{\mu} & =w_{1} h_{11} \exp \left(\delta_{1} t\right)+w_{2} h_{21} \exp \left(\delta_{2} t\right), \\
m_{t}-m_{s s} & =w_{1} h_{12} \exp \left(\delta_{1} t\right)+w_{2} h_{22} \exp \left(\delta_{2} t\right), \\
c_{t}-\bar{y} & =w_{1} h_{13} \exp \left(\delta_{1} t\right)+w_{2} h_{23} \exp \left(\delta_{2} t\right),
\end{aligned}
$$

where $w_{i}, i=1,2$, denotes the constant associated with root $\delta_{i}$. Since $\delta_{2}-$ $\delta_{1}<0$, it follows that:

$$
\lim _{t \rightarrow \infty} \frac{\pi_{t}-\bar{\mu}}{m_{t}-m_{s s}}=\frac{h_{11}}{h_{12}}>0 .
$$

This implies that as $t$ becomes large, inflation and real money balances will converge to their steady-state values from the same direction. Put differently, the "dominant eigenvector ray," which is illustrated in Figure 1, is positively sloped (see Calvo (1987)). Graphically, the system must converge asymptotically to the dominant eigenvector ray. From (14), we also know that when $\pi_{t}>\bar{\mu}\left(\pi_{t}<\bar{\mu}\right)$, real money balances are falling (rising). The corresponding directional arrows are drawn in Figure 1.

We now have all the elements needed to study how this economy adjusts to an unanticipated and permanent fall in the rate of monetary growth. Suppose 
that in the initial steady-state (i.e., for $t<0$ ), the rate of monetary growth is $\bar{\mu}^{H}$. At $t=0$, policymakers announce an unanticipated and permanent reduction of the money growth rate from $\bar{\mu}^{H}$ to $\bar{\mu}^{L}$, where $\bar{\mu}^{H}>\bar{\mu}^{L}$. In terms of Figure 1, the initial high-inflation steady-state is at point A. The new steady state — with lower inflation and higher real money balances is at point B. Given the conditions that must be satisfied by a convergent path, the economy must follow the arrowed path illustrated in Figure $1 .{ }^{7}$

Figure 2 illustrates the time path of the main variables. The paths of inflation and real money balances follow directly from Figure 1. Since the inflation rate is a predetermined variable, the reduction in the rate of monetary growth implies that real money balances fall in the early stages. Given the path of $m_{t}$, the path of $i_{t}$ follows from (5). The nominal interest rate must rise early on to accommodate the lower level of real money balances. Since $r_{t}=i_{t}-\pi_{t}$, the path of $r_{t}$ follows from the paths of $i_{t}$ and $\pi_{t} .{ }^{8}$ The fact that $r_{t}$ is above $\beta$ during all the adjustment process implies that, after jumping downward on impact, consumption rises throughout.

The intuition behind the results just discussed is as follows. The permanent reduction in the rate of monetary growth implies that, in the new steady-state, inflation, and thus the nominal interest rate, will be lower. Hence, real money demand in the new steady-state will be higher. How will this increase in real money balances come about? Since the nominal money stock does not jump at $t=0$ (it is a policy variable), the only way for the economy to generate higher real money balances is for the inflation rate to fall below the lower rate of monetary growth, $\bar{\mu}^{L}$. Hence, inflation needs to "undershoot" its long-run value for real money balances to eventually begin to rise toward their higher steady-state value. Put differently, "tight" monetary policy (in the form of a sharp reduction in the rate of monetary growth) forces the economy to undergo a deflationary period. This "tight" monetary policy manifests itself in high nominal and real interest rates in the early stages of the stabilization.

It will prove useful to derive analytically the time paths of the nominal and real interest rates. Differentiating first-order condition (5) and recalling

\footnotetext{
${ }^{7}$ As formally shown in the Appendix, it can be ruled out that, starting from point A, the system will first head in a northwestern direction. In other words, $\dot{\pi}_{0}<0$. To show this, we first must show that consumption jumps downwards on impact (see Appendix).

${ }^{8}$ In principle, we cannot rule out that the slope of the path of $r_{t}$ changes sign more than once. What is important, however, is that, during the adjustment process, $r_{t}$ will always be above its unique steady-state value.
} 
that $\dot{m}_{t} / m_{t}=\bar{\mu}-\pi_{t}$, it follows that

$$
\dot{i}_{t}=m_{t} v^{\prime \prime}\left(m_{t}\right)\left(\pi_{t}-\bar{\mu}^{L}\right) .
$$

Hence, along the adjustment path, the nominal interest rate depends on the difference between the current inflation rate and the long-run inflation rate (which equals $\bar{\mu}^{L}$ ). As made clear below, this already suggests that an inflation target combined with an interest rate rule whereby the nominal interest rate is raised if the actual inflation rate is above the inflation target may yield a similar dynamic path to the $\mathrm{k}$-percent money growth rule.

As far as the real interest rate is concerned, using the Fischer equation and equations (13) and (26), we obtain:

$$
\dot{r}_{t}=\left[\gamma+m_{t} v^{\prime \prime}\left(m_{t}\right)\right]\left(\pi_{t}-\bar{\mu}^{L}\right)-\alpha\left(c_{t}-\bar{y}\right) .
$$

Hence, the real interest rate increases whenever inflation is above its long-run value and falls if consumption is above the full-employment level of output. The intuition for the latter channel is as follows: other things being equal, when consumption is above its full employment level, the inflation rate is rising (recall (13)), which implies that the real interest rate is falling. Again, this suggests that an inflation target combined with a real interest rate rule which responds to both (a) the gap between the current inflation rate and an inflation target and (b) the output gap should yield similar dynamics to the k-percent money growth rule.

\section{The nominal interest rate as an instrument}

\subsection{A pure interest rate peg}

Suppose that policymakers set the nominal interest rate at a constant level $\bar{i}$. This is achieved by letting the money supply adjust to whatever level is needed for the targeted interest rate to prevail. It will be shown that an interest rate peg leads to a multiplicity of equilibrium paths.

If $i_{t}=\bar{i}$, it follows from first-order condition (5) that $\dot{m}_{t}=0$, and therefore that $\pi_{t}=\mu_{t}$. Equation (10) then becomes

$$
\dot{\pi}_{t}=\alpha\left(c_{t}-\bar{y}\right)
$$


Taking into account the Fisher equation, the Euler equation (8) can be rewritten as

$$
\dot{c}_{t}=\frac{u^{\prime}\left(c_{t}\right)}{u^{\prime \prime}\left(c_{t}\right)}\left(\beta+\pi_{t}-\bar{i}\right) .
$$

Equations (28) and (29) constitute a differential equation system in $\pi_{t}$ and $c_{t}$, for a given value of $\bar{i}$. At the steady-state, $c_{s s}=\bar{y}$ and $\pi_{s s}=\bar{i}-\beta$. Linearizing the system around the steady-state:

$$
\left[\begin{array}{l}
\dot{\pi}_{t} \\
\dot{c}_{t}
\end{array}\right]=\left[\begin{array}{ll}
0 & \alpha \\
\frac{u^{\prime}(\bar{y})}{u^{\prime \prime}(\bar{y})} & 0
\end{array}\right]\left[\begin{array}{l}
\pi_{t}-\pi_{s s} \\
c_{t}-\bar{y}
\end{array}\right] .
$$

The trace and determinant of the matrix associated with the linear approximation are given by, respectively,

$$
\begin{aligned}
\operatorname{Tr} & =0, \\
\Delta & =-\alpha \frac{u^{\prime}(\bar{y})}{u^{\prime \prime}(\bar{y})}>0 .
\end{aligned}
$$

This implies that there are two complex roots with real part equal to zero. ${ }^{9}$ The dynamic system exhibits a "vortex" and is thus unstable. For a given initial value of the inflation rate (except if it happens to be the steadystate value), there is no value of consumption which places the economy on a convergent path. All possible values imply that the system will oscillate forever without ever reaching the steady-state. Therefore, in this model a pure nominal interest rate peg does not provide a sensible way of conducting monetary policy.

Intuitively, the problem lies in the fact that, under a pure interest rate peg, the economy loses its nominal anchor as the rate of monetary growth passively accommodates inflation. Indeed, as made clear by equation (28), there is no long-run value of the inflation rate (i.e., no nominal anchor) to guide the inflation rate to a specific value. In contrast, under a k-percent money rule (recall equation (13)), the rate of change of the inflation rate is affected by the difference between the current inflation rate and its long-run value.

\footnotetext{
${ }^{9}$ The roots are given by $\delta_{1,2}= \pm \sqrt{-\alpha} z \sqrt{-\frac{u^{\prime}(\bar{y})}{u^{\prime \prime}(\bar{y})}}$, where $z^{2}=-1$.
} 


\subsection{A nominal interest rate rule with an inflation tar- get}

Consider the following policy regime: policymakers announce an inflation target, $\bar{\pi}$, and follow the interest rate rule

$$
\dot{i}=\theta\left(\pi_{t}-\bar{\pi}\right)
$$

whereby the nominal interest rate is raised (reduced) in a gradual way whenever the inflation rate is above its target. ${ }^{10}$ (Note that in this set-up, the nominal interest rate is by construction a predetermined variable.) Differentiating first-order condition (5) and using (30), we get:

$$
\dot{m}_{t}=\frac{-\theta}{v^{\prime \prime}\left(m_{t}\right)}\left(\pi_{t}-\bar{\pi}\right) .
$$

Combining the last equation with (10) and (12) yields

$$
\dot{\pi}_{t}=\frac{\gamma \theta}{m_{t} v^{\prime \prime}\left(m_{t}\right)}\left(\bar{\pi}-\pi_{t}\right)+\alpha\left(c_{t}-\bar{y}\right) .
$$

The last equation, together with (15) and (31) form a dynamic system in $\pi_{t}, m_{t}$, and $c_{t}$ whose dynamic properties are qualitatively the same as those of the system (13), and (14), (15) studied for the fixed money growth rule. Hence, if at time 0 , policymakers announce a reduction in the inflation target and follow policy rule (30), the economy will follow (in qualitative terms) the adjustment process depicted in Figure 2, except for $\mu_{t}$.

Notice that $\mu_{t}$ is now an endogenous variable whose path is given by:

$$
\mu_{t}=\frac{\theta}{m_{t} v^{\prime \prime}\left(m_{t}\right)} \bar{\pi}+\left[1-\frac{\theta}{m_{t} v^{\prime \prime}\left(m_{t}\right)}\right] \pi_{t} .
$$

To fix ideas, notice that $m_{t} v "\left(m_{t}\right)$ is the inverse of the (absolute value of the) semi-elasticity of real money demand (denoted by $\eta^{s}$ ); that is, $\eta_{t}^{s} \equiv \frac{1}{m_{t} v^{\prime \prime}\left(m_{t}\right)}$. If real money demand is of the Cagan-type (i.e., it exhibits a constant semielasticity), then it follows from (33) that on impact $\mu_{t}$ will fall by more than the inflation target if $\eta^{s}>1 / \theta$ and by less if $\eta^{s}<1 / \theta$. In the case in which $\eta^{s}=1 / \theta, \mu_{t}=\bar{\pi}$ for all $t$, and the system behaves exactly as it does under a fixed-money growth rule. In other words, an outside observer would not

\footnotetext{
${ }^{10}$ Unless otherwise indicated, all policy pameters are positive.
} 
be able to tell whether a given reduction in the long-run inflation rate was brought about by a permanent reduction in $\bar{\mu}$ or by the announcement of a lower inflation target together with interest rate rule (30).

\section{The real interest rate as policy instrument}

\subsection{A pure real interest rate peg}

Suppose that policymakers set the real interest rate at the constant value $\bar{r}$. A necessary condition for such a real interest rate peg to be consistent with a convergent equilibrium path is that $\bar{r}=\beta$. Otherwise, consumption would either increase or decrease forever, as follows from (8). The peg $\bar{r}=\beta$ therefore implies that $\dot{c}_{t}=0$. Hence, $c_{t}=\bar{y}$ for a convergent path to exist. From (10),

$$
\dot{\pi}_{t}=\gamma\left(\mu_{t}-\pi_{t}\right) .
$$

Recalling the Fisher equation, it then follows from (7) and (34) that

$$
\dot{\pi}_{t}\left[\frac{1}{\gamma}-\frac{L^{\prime}\left(i_{t}\right)}{L\left(i_{t}\right)}\right]=0,
$$

which implies that, along a perfect foresight equilibrium path, $\dot{\pi}_{t}=0$. Intuitively, if the rate of monetary growth were, say, above the inflation rate, real money balances would be increasing over time. For money market equilibrium to hold, the nominal interest rate would need to fall over time. Since the real interest rate is constant, this implies that the inflation rate would be falling over time. On the other hand, if the rate of monetary growth were above the inflation rate, equation (34) indicates that inflation must be increasing over time. The only consistent path is for inflation to remain flat over time.

Let $\pi_{t}=\bar{\pi}$. Hence, along a perfect foresight equilibrium path, $\mu_{t}=\bar{\pi}$, $i_{t}=\bar{r}+\bar{\pi}$, and $m_{t}=L(\bar{r}+\bar{\pi})$. The economy is thus always in a stationary equilibrium. This equilibrium, however, is not uniquely determined. To see this, suppose that, for whatever reason, the public came to expect that the inflation rate will be $2 \bar{\pi}$. Then, by the above reasoning, $\mu_{t}=2 \bar{\pi}$ and $i_{t}=\bar{r}$ $+2 \bar{\pi}$. Since the nominal interest rate is higher, real money demand would be lower; that is, $m_{t}=L(\bar{r}+2 \bar{\pi})$. The nominal money stock would fall 
to accommodate the lower real money demand. In sum, policymakers will validate any inflation rate expected by the public. There is nothing to tie down the level of the constant rate of inflation.

\subsection{A real interest rate rule with an inflation target}

Consider the following policy regime: policymakers announce an inflation target, $\bar{\pi}$, and follow the real interest rate rule

$$
\dot{r}_{t}=\theta\left(\pi_{t}-\bar{\pi}\right),
$$

Combining (7), (10), and (35), we get:

$$
\dot{\pi}_{t}=\frac{\theta \gamma \frac{L^{\prime}\left(i_{t}\right)}{L\left(i_{t}\right)}}{1-\gamma \frac{L^{\prime}\left(i_{t}\right)}{L\left(i_{t}\right)}}\left(\pi_{t}-\bar{\pi}\right)+\frac{\alpha}{1-\gamma \frac{L^{\prime}\left(i_{t}\right)}{L\left(i_{t}\right)}}\left(c_{t}-\bar{y}\right) .
$$

Equations (8), (35), and (36) constitute a dynamic system in $\pi_{t}, c_{t}$, and $r_{t}$. Proceeding as in the case of the fixed money-growth rule, this dynamic system

may be solved by computing the dominant eigenvector ray. In response to an unanticipated reduction in the inflation target, the system adjusts to the new steady-state following similar dynamics as in Figure 2, except for the behavior of $\mu_{t}$, which may vary over time.

\section{An equivalence proposition}

It has been shown above that both a nominal interest rate rule and a real interest rate rule, in conjunction with an inflation target, will yield qualitatively the same results as a $\mathrm{k}$-percent money growth rule. We now show a particular case in which these three rules are exactly the same.

Suppose that the transactions costs technology takes the form:

$$
v\left(m_{t}\right)=m_{t}\left[\frac{1}{\sigma} \log \left(m_{t}\right)-\chi\right]
$$

where $\chi$ is a positive parameter. Then, using (5), the real money demand becomes:

$$
m_{t}=A e^{-\sigma i_{t}}, \quad A \equiv e^{\sigma \chi-1}
$$


This is a Cagan-type real money demand since it exhibits a constant semielasticity:

$$
\eta^{s}\left(m_{t}\right) \equiv \frac{-\partial L\left(i_{t}\right)}{\partial i_{t}} \frac{1}{m_{t}}=\frac{1}{m_{t} v^{\prime \prime}\left(m_{t}\right)}=\sigma .
$$

Under such a specification, the paths for the nominal interest rate and the real interest rate for the k-percent money growth rule studied above are given by, respectively (as follows from (26), (27), and (39)):

$$
\begin{aligned}
& \dot{i}_{t}=\frac{1}{\sigma}\left(\pi_{t}-\bar{\mu}\right) . \\
& \dot{r}_{t}=\left(\gamma+\frac{1}{\sigma}\right)\left(\pi_{t}-\bar{\mu}\right)-\alpha\left(c_{t}-\bar{y}\right) .
\end{aligned}
$$

Equation (40) indicates that, under a Cagan money demand, the rate of change of the nominal interest rate is a linear function of the gap between the current inflation rate and the long-run inflation rate (given by $\bar{\mu}$ ). From (41), it follows that the rate of change of the real interest rate is also a linear function of the inflation gap and, in addition, of the gap between consumption (aggregate demand) and full-employment output. Recall also from Figure 2 that neither the nominal interest rate nor the real interest rate jump on impact (i.e., at $t=0$ ).

Suppose now that policymakers set an inflation target, $\bar{\pi}$, which pins down the long-run inflation rate and therefore plays the role of $\bar{\mu}$. In conjunction with this inflation target, they follow interest rate rules of the form (40) and (41), whereby the nominal interest rate and the real interest rate are changed gradually over time in response to changes in either the inflation gap or the output gap. Furthermore, suppose that policymakers set the policy reaction coefficients equal to $\frac{1}{\sigma}$ for the inflation gap in the case of the nominal interest rate rule and equal to $\gamma+\frac{1}{\sigma}$ for the inflation gap and $-\alpha$ for the output gap in the case of the real interest rate rule. Under these conditions, it follows that these two policy rules will be exactly equivalent to the fixed money growth-rule studied above.

We summarize this equivalence result in the following proposition:

Proposition 1 Suppose that the transactions technology is given by (37), which gives rise to a Cagan money demand function (38), with semi-elasticity 
equal to $\sigma$. Then, the following three monetary policy rules are exactly equivalent:

(a) policymakers set a fixed-money growth rule:

$$
u_{t}=\bar{\mu}
$$

(b) policymakers announce an inflation target, $\bar{\pi}$ (equal to $\bar{\mu}$ ), and follow the nominal interest rate rule

$$
\dot{i}_{t}=\theta\left(\pi_{t}-\bar{\mu}\right), \quad \theta=\frac{1}{\sigma}
$$

(c) policymakers announce an inflation target, $\bar{\pi}$ (equal to $\bar{\mu}$ ), and follow the real interest rate rule

$$
\dot{r}_{t}=\theta^{1}\left(\pi_{t}-\bar{\mu}\right)+\theta^{2}\left(c_{t}-\bar{y}\right), \quad \theta^{1}=\gamma+\frac{1}{\sigma}, \theta^{2}=-\alpha .
$$

This policy equivalence implies that if policymakers wish to reduce inflation, any of the three policy regimes are formally equivalent. Assuming that the model is a reasonably good description of reality, the choice between different rules will come down to practical advantages. Several remarks are in order:

(a) As one moves from the more orthodox instrument (the money supply) to the less orthodox instrument (the real interest rate), the rules become more complicated in the sense that more feedback mechanisms are required. Hence, in practice, these policy rules will be increasingly complex to implement.

(b) The real interest rule rate is not only the more complicated (as it depends on the output gap which is clearly difficult to estimate in practice) but does not have, in principle, any advantage over the nominal interest rate. In addition, the real interest rate rule requires that the real interest rate be reduced when there is excess aggregate demand, which is the opposite of what the public may thought should be done. ${ }^{11}$ This might lead to credibility problems.

(c) In practice, monetary authorities have mostly abandoned money growth rules based principally on the instability of money demand and the problems

\footnotetext{
${ }^{11}$ Of course, a real interest rate rule of the form (35) - which does not respond to the output gap - can still deliver a qualitatively similar adjustment to the fixed money-growth rule, although it cannot replicate it exactly. Even in this case, however, the real interest rate does not have any advantages over the nominal interest rate as a policy instrument.
} 
associated with choosing between different monetary aggregates. A nominal interest rate rule avoids this problem and therefore could be preferable. This might explain the increasing popularity of inflation targeting regimes, of which rule (30) may be considered a particular case.

\section{Avoiding deflation: Alternative rules}

A legitimate question that may arise is why should the fixed-money growth rule be the benchmark against which other rules are compared. There are several reasons that make it the natural benchmark. First, it is the traditional policy instrument par excellence. Second, as shown above, it is the only instrument that can be set with no feedback rules. In the absence of feedback rules, neither the nominal nor the real interest rate can provide a nominal anchor for monetary policy.

In spite of the above, there is a case to be made to consider other possible benchmarks. The main rationale for doing so is the fact that, as discussed above, a fixed money-growth rule represents in some sense an excessively tight monetary policy stance as it requires a prolonged period of deflation (in the sense of the inflation rate falling below its long-run value) in order to build real money balances, as illustrated in Figure 2, Panel B. One may therefore wonder whether there may not be other rules which could avoid this deflationary period and thus provide a better benchmark.

Since the excessively tight monetary policy is reflected in an initial fall in consumption, it seems natural to ask whether an interest rate rule which also responds to the output gap would be capable of avoiding the deflationary period. ${ }^{12}$

\subsection{A nominal interest rate rule with output feedback}

Suppose that, instead of (30), the interest rate rule takes the form:

$$
\dot{i}=\theta\left(\pi_{t}-\bar{\pi}\right)+\xi\left(c_{t}-\bar{y}\right) .
$$

This rule captures policymakers' concerns with consumption (and thus output) falling below its full-employment level. If consumption is below its

\footnotetext{
${ }^{12}$ For simplicity, we will consider the case in which real money demand is given by (38).
} 
full-employment level, the nominal interest rate is reduced. ${ }^{13}$

Using (5), (10), and the fact that $\dot{m}_{t} / m_{t}=\mu_{t}-\pi_{t}$, we get

$$
\dot{\pi}_{t}=\gamma \theta \eta^{s}\left(\bar{\pi}-\pi_{t}\right)+\left(\alpha-\gamma \xi \eta^{s}\right)\left(c_{t}-\bar{y}\right) .
$$

Since we are mainly interested in providing an example in which a nominal interest rate with output feedback avoids the deflationary period, we will consider the case in which $\alpha-\gamma \xi \eta^{s}=0 .{ }^{14}$ Equation (46) then simplifies to:

$$
\dot{\pi}_{t}=\gamma \theta \eta^{s}\left(\bar{\pi}-\pi_{t}\right) .
$$

Since this is a stable differential equation in $\pi_{t}$, it follows immediately that an unanticipated and permanent reduction in the inflation target combined with rule (45) will lead to inflation falling monotonically over time towards its lower steady-state value.

To solve for the whole dynamic system, combine the Fisher equation and equations (45) and (47) to obtain the law of motion for the real interest rate:

$$
\dot{r}_{t}=\theta\left(1+\gamma \eta^{s}\right)\left(\pi_{t}-\bar{\pi}\right)+\xi\left(c_{t}-\bar{y}\right) .
$$

Notice that, unlike in the k-percent money growth rule case in which $\dot{r}_{t}$ depended negatively on excess demand (recall equation (41)), here it depends positively. The intuition in this case is as follows. Excess demand does not directly affect the change in the inflation rate, as follows from (47). Hence, other things being equal, excess aggregate demand leads to an increase in the nominal interest rate - according to rule (45) - and hence in the real interest rate.

Equations (8), (47) and (48) form a differential equation system in $\pi_{t}$, $r_{t}$, and $c_{t}$. Both $\pi_{t}$ and $r_{t}$ are predetermined variables. ${ }^{15}$ Linearizing this system around the steady-state, we obtain:

$$
\left[\begin{array}{l}
\dot{\pi}_{t} \\
\dot{r}_{t} \\
\dot{c}_{t}
\end{array}\right]=\left[\begin{array}{lll}
-\gamma \theta \eta^{s} & 0 & 0 \\
\theta\left(1+\gamma \eta^{s}\right) & 0 & \xi \\
0 & \frac{-u^{\prime}(\bar{y})}{u^{\prime \prime}(\bar{y})} & 0
\end{array}\right]\left[\begin{array}{l}
\pi_{t}-\bar{\pi} \\
r_{t}-\beta \\
c_{t}-\bar{y}
\end{array}\right]
$$

\footnotetext{
${ }^{13}$ The policy rule captured in equation $(45)$ is, of course, in line with the so-called "Taylor rule"; see Taylor (1993).

${ }^{14}$ This implies assuming that policymakers set $\xi=\frac{\alpha}{\gamma \eta^{s}}$ in the policy rule given by equation (45).

${ }^{15}$ Note that by construction $i_{t}$ is predetermined. Since $\pi_{t}$ is also a predetermined variable, so is $r_{t}$.
} 
The trace and determinant of the matrix associated with the linear approximation are, respectively,

$$
\begin{aligned}
T r & =-\gamma \theta \eta^{s}<0, \\
\Delta & =\frac{u^{\prime}(\bar{y})}{-u^{\prime \prime}(\bar{y})} \xi \gamma \theta \eta^{s}>0 .
\end{aligned}
$$

The system has therefore two negative roots. ${ }^{16}$ Let $\delta_{i}, i=1,2$, denote the two negative roots. ${ }^{17}$ Let $h_{i j}, j=1,2,3$, denote the elements of the eigenvector associated with root $\delta_{i}$. Hence, for $i=1,2$, it follows that

$$
\left[\begin{array}{lll}
-\gamma \theta \eta^{s}-\delta_{i} & 0 & 0 \\
\theta\left(1+\gamma \eta^{s}\right) & -\delta_{i} & \xi \\
0 & \frac{-u^{\prime}(\bar{y})}{u^{\prime \prime}(\bar{y})} & -\delta_{i}
\end{array}\right]\left[\begin{array}{l}
h_{i 1} \\
h_{i 2} \\
h_{i 3}
\end{array}\right]=\left[\begin{array}{l}
0 \\
0 \\
0
\end{array}\right]
$$

Therefore,

$$
\frac{h_{i 2}}{h_{i 3}}=\frac{\delta_{i}}{\frac{-u^{\prime}(\bar{y})}{u^{\prime \prime}(\bar{y})}}<0 .
$$

Setting to zero the constant corresponding to the unstable root, the solution to this dynamic system takes the form (notice that $h_{21}=0$ ):

$$
\begin{aligned}
\pi_{t}-\bar{\pi} & =w_{1} h_{11} \exp \left(\delta_{1} t\right) \\
r_{t}-\beta & =w_{1} h_{12} \exp \left(\delta_{1} t\right)+w_{2} h_{22} \exp \left(\delta_{2} t\right) \\
c_{t}-\bar{y} & =w_{1} h_{13} \exp \left(\delta_{1} t\right)+w_{2} h_{23} \exp \left(\delta_{2} t\right)
\end{aligned}
$$

where $w_{i}, i=1,2$, denotes the constant associated with root $\delta_{i}$. Since $\delta_{1}-$ $\delta_{2}<0$, it follows that:

$$
\lim _{t \rightarrow \infty} \frac{r_{t}-\beta}{c_{t}-\bar{y}}=\frac{h_{12}}{h_{13}}<0 .
$$

\footnotetext{
${ }^{16}$ Since one of the negative roots is $-\gamma \theta \eta^{s}$, it follows that the two negative roots are real numbers.

${ }^{17}$ The roots are $\delta_{1}=-\gamma \theta \eta^{s}$ and $\delta_{2}=-\sqrt{\xi \frac{u^{\prime}(\bar{y})}{-u^{\prime \prime}(\bar{y})}}$. (It will be assumed, with no loss of generality, that $\delta_{1}<\delta_{2}$.)
} 
This implies that as $t$ becomes large, the real interest rate and consumption will converge to their steady-state values from opposite directions. In other words, the dominant eigenvector ray is negatively sloped (Figure 3). From (8), it follows that consumption increases (falls) to the right (left) of $r_{t}=\beta$. The corresponding directional arrows are drawn in Figure 3.

Let us now study the economy's response to a reduction in the inflation target, $\bar{\pi}$. Suppose that in the initial steady-state (i.e., for $t<0$ ), the inflation target is $\bar{\pi}^{H}$. (The initial steady-state is denoted by point A in Figure 3.) At $t=0$, policymakers announce an unanticipated and permanent reduction of the inflation target from $\bar{\pi}^{H}$ to $\bar{\pi}^{L}$, where $\bar{\pi}^{H}>\bar{\pi}^{L}$. Notice that, in terms of Figure 3, the steady-state remains at point A. In order to be on a convergent path, $c_{t}$ must jump down on impact to a point such as B. ${ }^{18}$ The system then follows the arrowed path back to point A.

Figure 4 (full line) illustrates the time path of the main variables. If $\theta=\frac{1}{\eta^{s}}$, the path of the rate of monetary growth is given by

$$
\mu_{t}=\bar{\pi}^{L}-\frac{\xi}{\theta}\left(c_{t}-\bar{y}\right)
$$

Hence, on impact the money growth rate will fall by less than the inflation target. During the transition, the rate of money growth must be higher (at least during some period of time) than the inflation rate to allow real money balances to grow over time without the need for inflation to fall below its steady-state value. Real money balances fall in the initial stages and increase later on (panel C) and the nominal interest rate increases early on and falls later on (panel D).

Depending on the parameter configuration, the rate of money growth rate could rise on impact (as captured by the dashed path in panel A). ${ }^{19}$ In that case, real money balances will grow from the very beginning and the nominal interest rate would fall throughout the adjustment path (dashed paths in panels $\mathrm{C}$ and $\mathrm{E}$, respectively).

\footnotetext{
${ }^{18}$ If consumption did not jump downwards on impact, the system would diverge in a northeastern direction. To see this notice that, if $c_{0} \geq \bar{y}$, then $\dot{r}_{0}=\theta\left(1+\gamma \eta^{s}\right)\left(\pi_{0}-\right.$ $\bar{\pi})+\xi\left(c_{0}-\bar{y}\right)>0$. The rising real interest rate would in turn lead to a rising path of consumption.

${ }^{19}$ Simulations of the system suggest that, as one would expect, this happens for high values of $\xi$ (which, from (45), implies a larger response of the nominal interest rate to the output gap).
} 


\subsection{A second equivalence proposition}

It follows immediately from (49) that, in conjunction with an inflation target, a money growth rule which responds to the output gap would enable policymakers to reduce inflation while avoiding a protracted deflationary period. Furthermore, a real interest rate rule that took the form given by (48) would also avoid the deflationary period. Notice that a key feature of this rule is that now the real interest rate would be raised when the economy is overheated, unlike rule (44) which implies the opposite.

We have therefore established another equivalence between the different policy rules and instruments, which is summarized in the following proposition.

Proposition 2 Suppose that the transactions technology is given by (37), which gives rise to a Cagan money demand function (38), with semi-elasticity equal to $\sigma$. Then, the following three monetary policy rules are exactly equivalent (under the maintained assumption that $\theta=\frac{1}{\eta^{s}}$ ):

(a) policymakers announce an inflation target, $\bar{\pi}$, and follow the moneygrowth rule:

$$
\mu_{t}=\bar{\pi}-\xi \sigma(c-\bar{y})
$$

(b) policymakers announce an inflation target, $\bar{\pi}$, and follow the nominal interest rate rule:

$$
\dot{i}=\theta\left(\pi_{t}-\bar{\pi}\right)+\xi\left(c_{t}-\bar{y}\right),
$$

(c) policymakers announce an inflation target, $\bar{\pi}$, and follow the real interest rule:

$$
\dot{r}_{t}=\theta^{1}\left(\pi_{t}-\bar{\pi}\right)+\theta^{2}\left(c_{t}-\bar{y}\right), \quad \theta^{1}=\theta(1+\gamma \sigma), \theta^{2}=\xi .
$$

It is still the case that the money rule is the simplest one. On the other hand, all rules depend on the output gap, which is naturally difficult to gauge in practice. From this point of view, therefore - and given the difficulties associated with money rules - the nominal interest rate-cum-inflation target policy regime continues to look like a very reasonable alternative to money rules. 


\section{Final remarks}

This paper has established some basic equivalences between alternative instruments and policy rules in the context of a sticky-inflation, closed-economy model. It has been shown that a long-run reduction in the inflation rate can be achieved with three different rules - a k-percent money growth rule, an interest rate rule, and a real interest rate rule - which deliver exactly the same outcome. The money rule is, however, the simplest as it involves no feedback mechanisms. If policymakers wish to avoid a protracted deflationary period, there are also three different policy regimes which deliver exactly the same outcome.

The goal of the analysis has been to put enough structure into the model so as to establish some basic policy equivalences, which should be helpful in thinking about alternative policy regimes. The main policy conclusion of the analysis is perhaps that a nominal interest rate rule combined with an inflation target can, in principle, replicate exactly the workings of a money growth rule. Taken as a normative result, it provides strong support for using nominal interest rate rules given the well-known practical difficulties of controlling monetary aggregates. As a positive implication, it may explain the dramatic shift in actual policymaking away from monetary targets and towards regimes which, in essence, involve — implicitly or explicitly — an inflation target and a nominal interest rate rule aimed at achieving that target.

How would the main conclusions of the analysis be affected by relaxing some of the main assumptions? While this remains an area for future research, some conjectures may be made. Let us consider the case of an open economy. In line with the spirit of the model, it could be assumed that prices of tradables goods are flexible and determined by purchasing power parity, while inflation of home goods is sticky and determined in the same way as in the closed-economy model. In such a model, and under flexible exchange rates, the same results should go through. The reason is simply that, under flexible exchange rates, the money supply remains the main nominal anchor; the same equivalences with interest rate rules would therefore hold. We would thus conjecture that, to a first approximation, our results should hold for flexible exchange rate regimes.

Under fixed or predetermined exchange rates, the nature of the policy rules studied in the paper would need to be modified to account for the fact that the nominal money supply is endogenous. This implies that, unlike in 
this paper's model, the nominal interest rate (and real interest rate) could jump on impact. Hence, one would need to study interest rate rules which may include an initial discrete change in interest rates. ${ }^{20}$ While this may complicate the formal analysis, I see no reason to believe that it would alter the main message of this paper.

What if the economy were subject to stochastic shocks? While this is an extension worth addressing, it should be pointed out that, from a conceptual level, it is not obvious why it should fundamentally alter any of the main conclusions. Suppose there were stochastic shocks to money demand. A k-percent money rule would absorb such shocks by variations in nominal (and, hence, real) interest rates. A nominal (or real) interest rate rule which responded to such shocks should deliver a similar outcome. If, on the other hand, certain type of shocks were more prevalent than others, this might affect the choice of instruments along the lines of Poole (1970), as analyzed by Subramanian (2001). It is unclear, however, how such considerations would affect the present analysis since the type of indeterminacies emphasized by the more modern, rational-expectations literature do not depend on the specific shocks which hit the economy.

\section{References}

[1] Auernheimer, Leonardo and Benjamin Contreras, "A Nominal Interest Rate Rule in the Open Economy," mimeo (Texas A\&M, 1993).

[2] Bruno, Michael, Crisis, Stabilization, and Reform: Therapy by Consensus (Oxford: Oxford University Press, 1993).

[3] Calvo, Guillermo A., "Real Exchange Rate Dynamics with Nominal Parities," Journal of International Economics, Vol. 22 (1987), pp. 141155.

[4] Calvo, Guillermo A., and Carmen M. Reinhart, "Fear of Floating," NBER Working Paper No. 7993 (2000).

[5] Calvo, Guillermo A., Carmen M. Reinhart, and Carlos A. Végh, "Targeting the Real Exchange Rate: Theory and Evidence," Journal of Development Economics, Vol. 47 (June 1995), pp. 97-133.

\footnotetext{
${ }^{20}$ Of course, the same logic would apply to a closed-economy model in which the real money demand also depended on consumption (which is not the case in this model).
} 
[6] Calvo, Guillermo A., and Carlos A. Végh, "Fighting Inflation with High Interest Rates: The Small Open Economy Case under Flexible Prices," Journal of Money, Credit and Banking, Vol. 27 (1995), pp. 49-66.

[7] Calvo, Guillermo A., and Carlos A. Végh, "Disinflation and InterestBearing Money" The Economic Journal, Vol. 106 (1996), pp. 1546-1563.

[8] Corbo, Vittorio, and Stanley Fischer, "Lessons from the Chilean Stabilization and Recovery," in Barry P. Bosworth, Rudiger Dornbusch, and Raul Laban, eds., The Chilean Economy (Washington, D.C.: The Brookings Institution), pp. 29-80.

[9] Dornbusch, Rudiger and Jacob Frenkel, "Inflation and Growth: Alternative Approaches," Journal of Money, Credit, and Banking, Vol. 5 (1973), pp. $141-56$.

[10] Dornbusch, Rudiger and Mario H. Simonsen, Inflation Stabilization with Incomes Policy Support: A Review of Recent Experience in Argentina, Brazil, and Israel (New York: Group of Thirty, 1987).

[11] Edwards, Sebastian, "Stabilization and Liberalization Policies in Central and Eastern Europe: Lessons from Latin America," NBER Working Paper No. 3816 (1991).

[12] Lahiri, Amartya, "Controlling Capital Flows: Targeting Stocks versus Flows", mimeo (UCLA, 1997).

[13] Lahiri, Amartya and Carlos A. Végh, "Living with the Fear of Floating: An Optimal Policy Perspective," NBER Working Paper No. 8391 (2001).

[14] Leiderman, Leonardo and Lars Svensson, eds., Inflation Targets (London: Center for Economic Policy Research, 1995).

[15] Lizondo, J. Saul, "Real Exchange Rate Targets, Nominal Exchange Rate Policies, and Inflation," Revista de Analisis Economico, Vol. 6 (1991), pp. 5-21.

[16] Masson, Paul R., Miguel A. Savastano, and Sunil Sharma, "The Scope for Inflation Targeting in Developing Countries," IMF Working Paper $97 / 130$. 
[17] Mendoza, Enrique, and Fernando Fernandez, "Monetary Transmission and Financial Indexation: Evidence from the Chilean Economy," PPAA 94/17 (IMF).

[18] Poole, William, "The Optimal Choice of Monetary Policy Instruments in a Simple Macro Model," Quarterly Journal of Economics, Vol. 84 (1970), pp. 192-216.

[19] Reinhart, Vincent, "The Design of an Interest Rate Rule with Staggered Contracting and Costly Transacting," Journal of Macroeconomics, Vol. 14 (1992), pp. 663-688.

[20] Reinhart, Vincent, "Real Interest Rates in the Monetary Policy Process," mimeo (Board of Governors of the Federal Reserve System, 1993).

[21] Rojas, Patricio, "El Dinero como un Objetivo Intermedio de la Politica Monetaria en Chile," Cuadernos de Economia, Vol. 30 (August 1993), pp. 139-178.

[22] Sargent, Thomas J. and Neil Wallace, "Rational Expectations, the Optimal Monetary instrument, and the Optimal Money Supply Rule," Journal of Political Economy, Vol. 83 (1975), pp. 241-254.

[23] Siklos, Pierre L., "Central Bank Behavior, the Institutional Framework, and Policy Regimes: Inflation vs. Non-Inflation Targeting Countries," mimeo (Wilfrid Laurier University, 2001).

[24] Subramanian, Chetan, "Optimal Choice of Monetary Policy Instruments," mimeo (USC, 2001).

[25] Svensson, Lars E.O., "Open-Economy Inflation Targeting," Journal of International Economics, Vol. 50 (2000), pp. 155-183.

[26] Taylor, John B., "Discretion versus Policy Rules in Practice," CarnegieRochester Conference Series on Public Policy, Vol. 39 (1993), pp. 195214 .

[27] Taylor, John B., "An Historical Analysis of Monetary Policy Rules," NBER Working Paper No. 6798 (1998). 


\section{Appendix: Fixed money growth rule}

Initial jump in consumption We now show that, following an unanticipated reduction in the rate of monetary growth, consumption must jump downwards on impact. We proceed in three stages.

First, we need to sign different elements of the eigenvectors. With no loss of generality, let $h_{11}=h_{21}=1$. Hence, from (22), it follows that

$$
\begin{aligned}
h_{12} & =-\frac{m_{s s}}{\delta_{1}}>0, \\
h_{22} & =-\frac{m_{s s}}{\delta_{2}}>0, \\
h_{22}-h_{12} & =m_{s s}\left(\frac{1}{\delta_{1}}-\frac{1}{\delta_{2}}\right)<0 .
\end{aligned}
$$

(To sign the last expression, recall that, by construction, $\delta_{1}-\delta_{2}>0$ ). Also, from (21), it follows that

$$
h_{i 3}=\frac{\gamma+\delta_{i}}{\alpha}, \quad i=1,2 .
$$

Second, we solve for the constants of the system. From the solution to the dynamic system, given by (23) - (25), we can write:

$$
\begin{aligned}
\pi_{0}-\bar{\mu}^{L} & =\omega_{1}+\omega_{2}, \\
m_{0}-m_{s s} & =\omega_{1} h_{12}+\omega_{2} h_{22}, \\
c_{0}-\bar{y} & =\omega_{1} h_{13}+\omega_{2} h_{23} .
\end{aligned}
$$

Using (54) and (55), we can solve for $\omega_{1}$ and $\omega_{2}$ :

$$
\begin{aligned}
& \omega_{1}=\frac{h_{22}\left(\pi_{0}-\bar{\mu}^{L}\right)-\left(m_{0}-m_{s s}\right)}{h_{22}-h_{12}}<0, \\
& \omega_{2}=\frac{m_{0}-m_{s s}-h_{12}\left(\pi_{0}-\bar{\mu}^{L}\right)}{h_{22}-h_{12}}>0,
\end{aligned}
$$

where the signs follow from (50)-(51) and the fact that $\pi_{0}-\bar{\mu}^{L}>0$ and $m_{0}-m_{s s}<0$. 
Finally, we can sign the expression for the initial jump in consumption. Substituting (53), (57), and (58) into (56) yields

$$
c_{0}-\bar{y}=\frac{1}{\alpha}\left[\frac{m_{0}-m_{s s}}{m_{s s}} \delta_{1} \delta_{2}+\left(\gamma+\delta_{1}+\delta_{2}\right)\left(\pi_{0}-\bar{\mu}^{L}\right)\right]<0 .
$$

To sign the last expression, notice that $\gamma+\delta_{1}+\delta_{2}<0$, which follows from the fact that $\delta_{1}+\delta_{2}+\delta_{3}+\gamma=0$ (recall, from (19), that the trace of the system is $-\gamma$ ) and $\delta_{3}>0$. Equation (59) implies that $c_{0}<\bar{y}$. Hence, consumption jumps downward on impact (i.e., at $t=0$ ).

Sign of $\dot{\pi}_{0}$ To check that, in terms of Figure 1, the system will not initially head in a northwestern direction starting from point A, it is enough to show that $\dot{\pi}_{0}<0$. To that effect, using equation (13), notice that

$$
\dot{\pi}_{0}=\gamma\left(\bar{\mu}^{L}-\pi_{0}\right)+\alpha\left(c_{0}-\bar{y}\right)<0,
$$

since $\bar{\mu}^{L}-\pi_{0}<0$ and, as just shown, $c_{0}-\bar{y}<0$. 
Figure 1. Dynamics in the $(m, \pi)$ plane

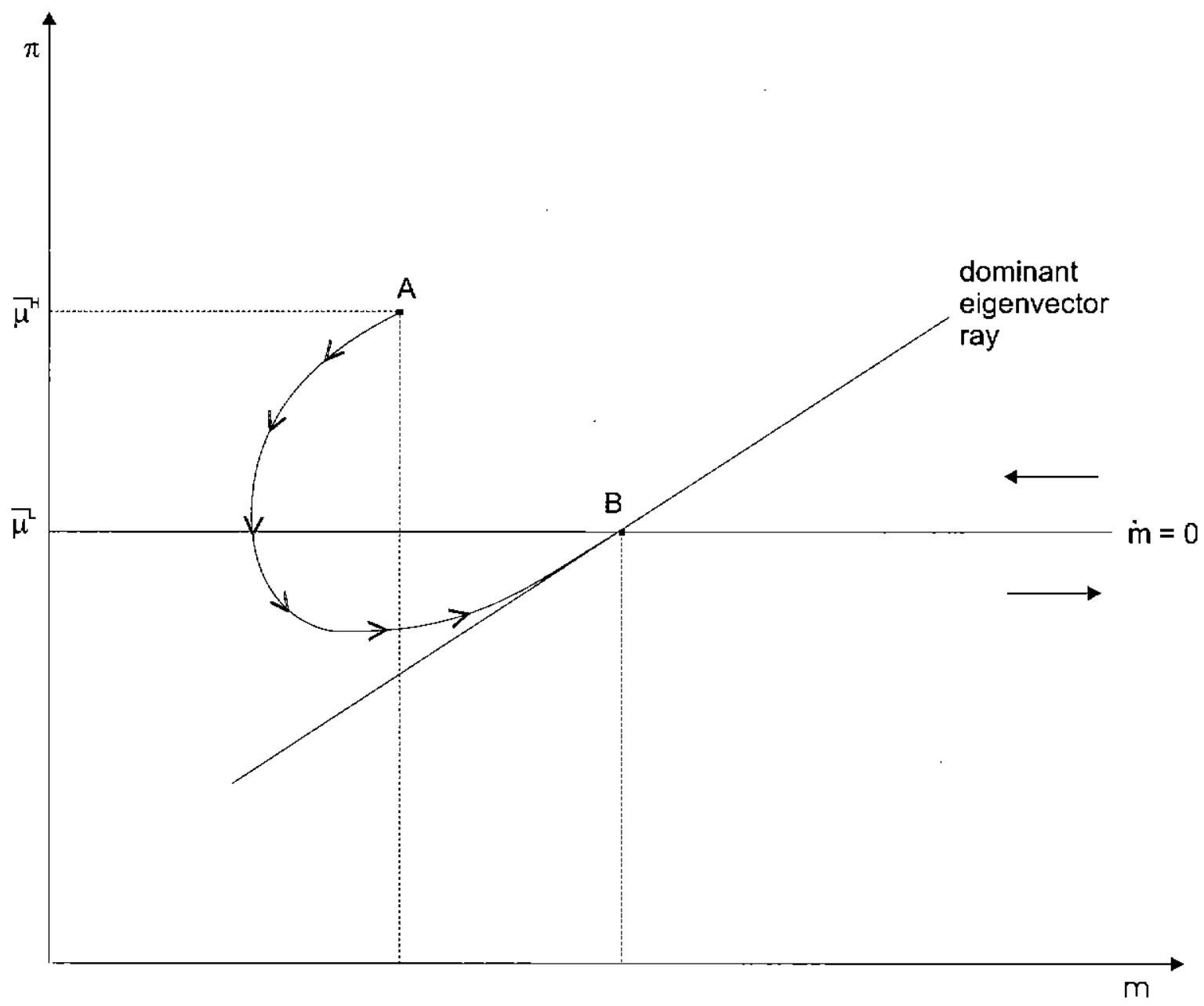


Figure 2. Reduction in money growth rate

A. Money growth rate

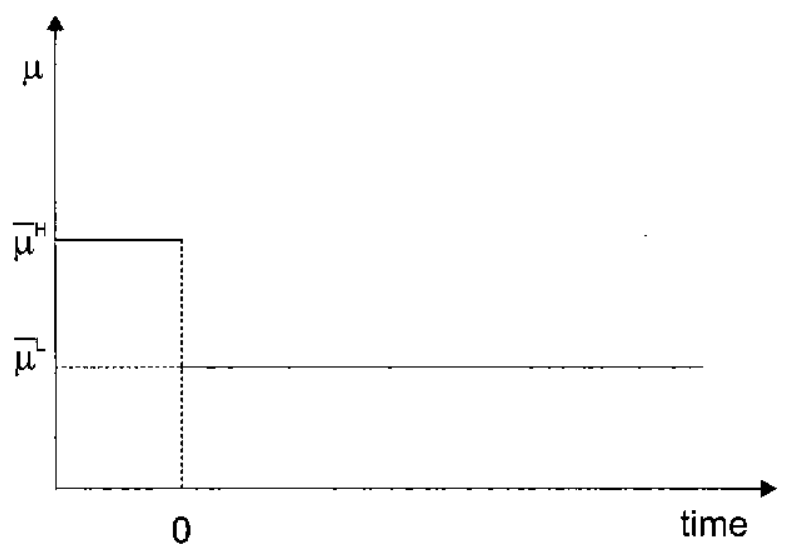

C. Real money balances

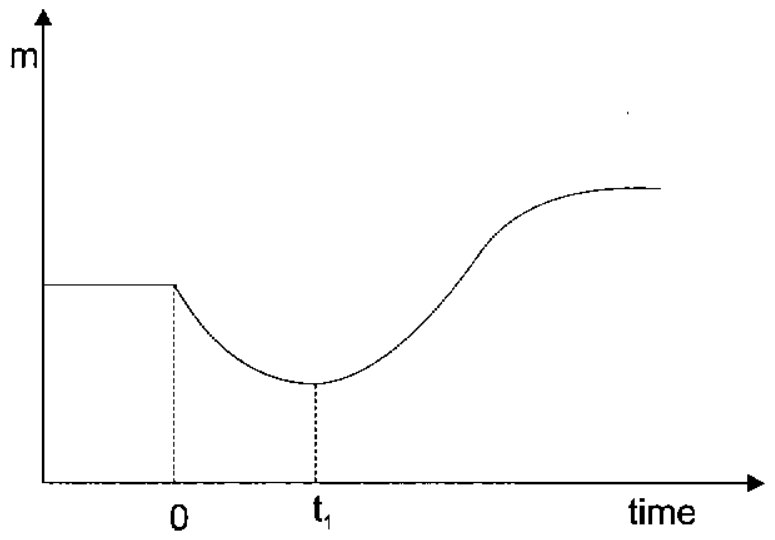

E. Nominal interest rate

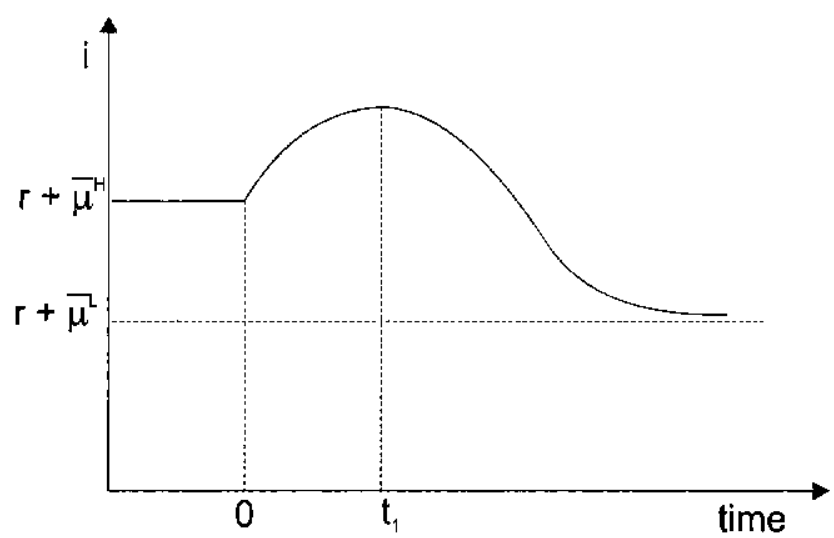

B. Inflation rate

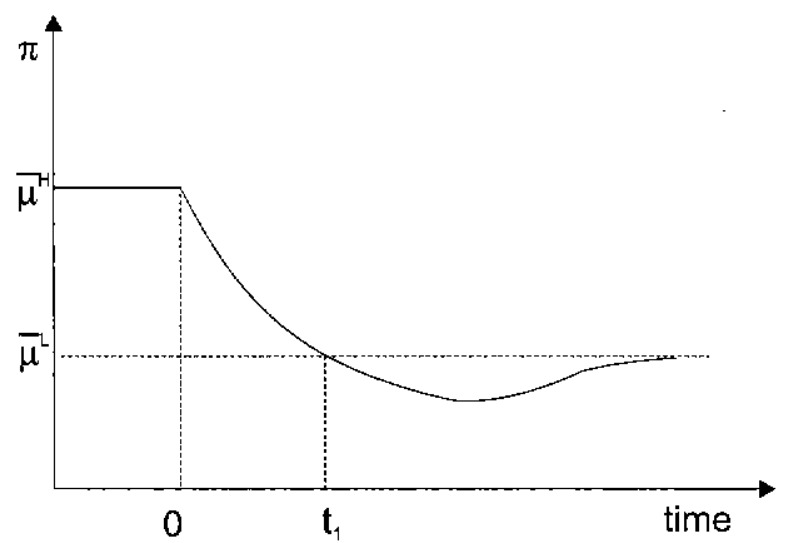

D. Consumption

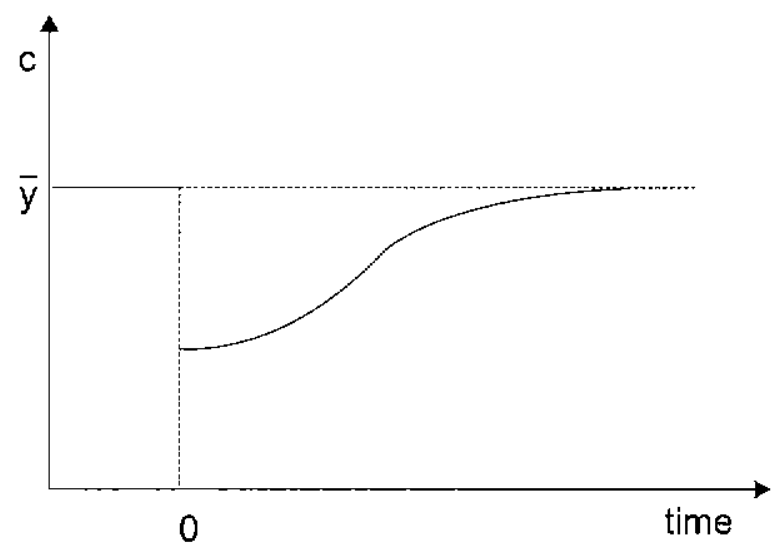

F. Real interest rate

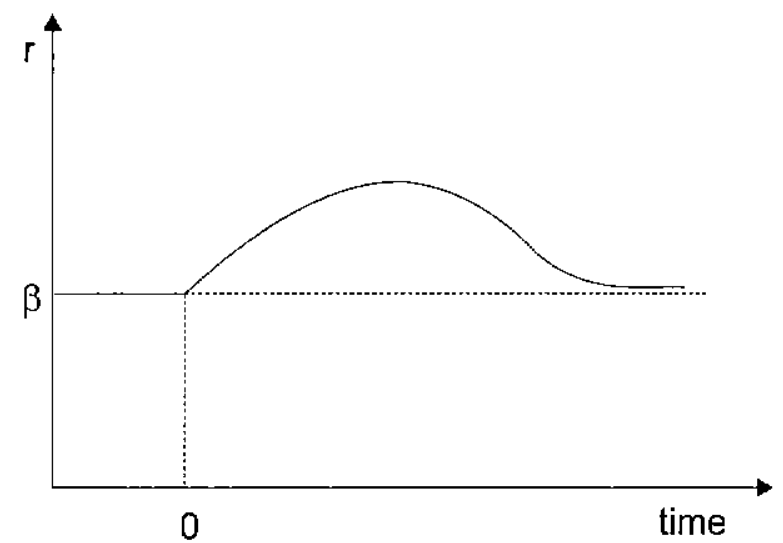


Figure 3. Dynamics in the $(r, c)$ plane

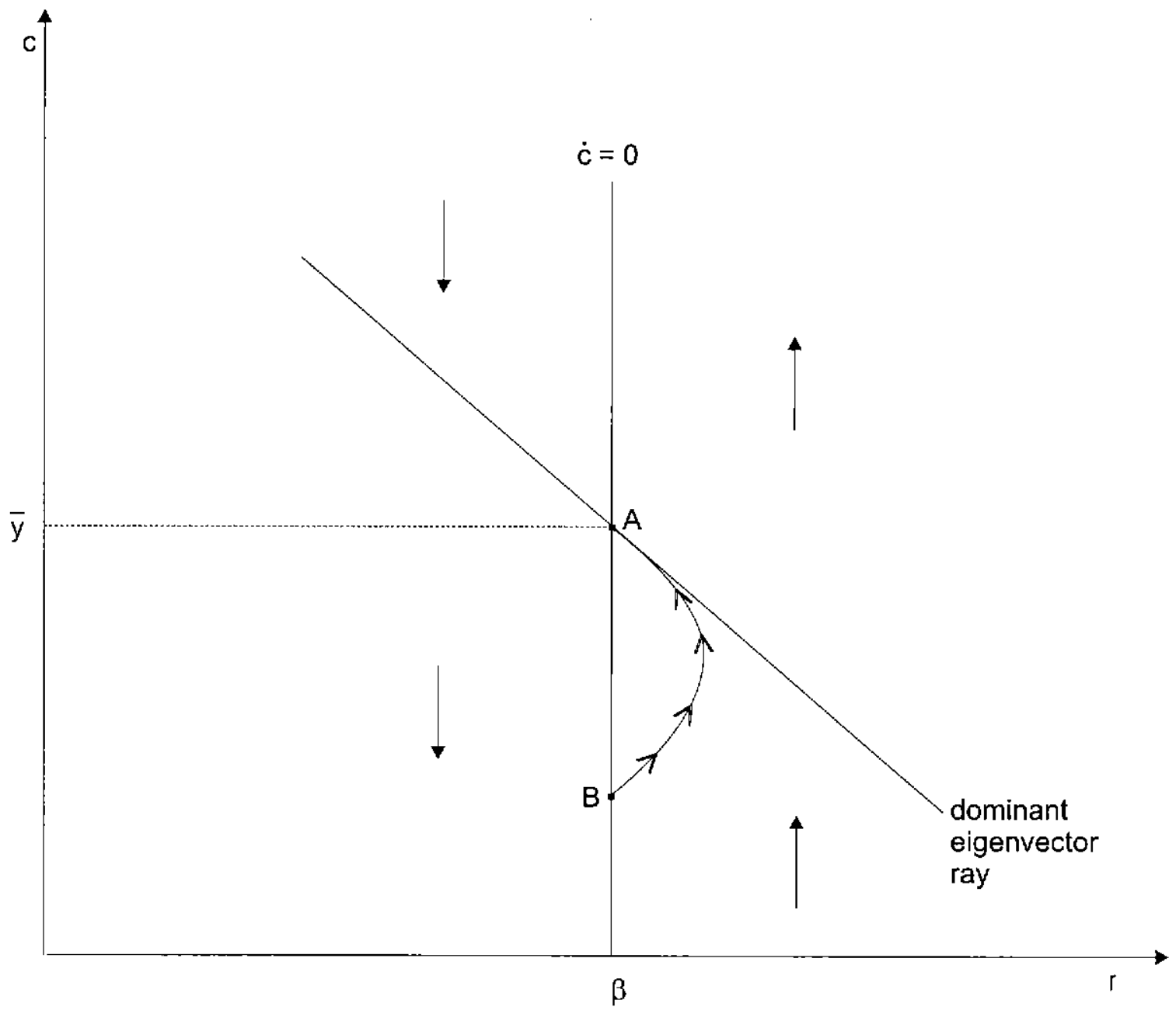


Figure 4. Reduction in inflation target
A. Money growth rate
B. Inflation rate
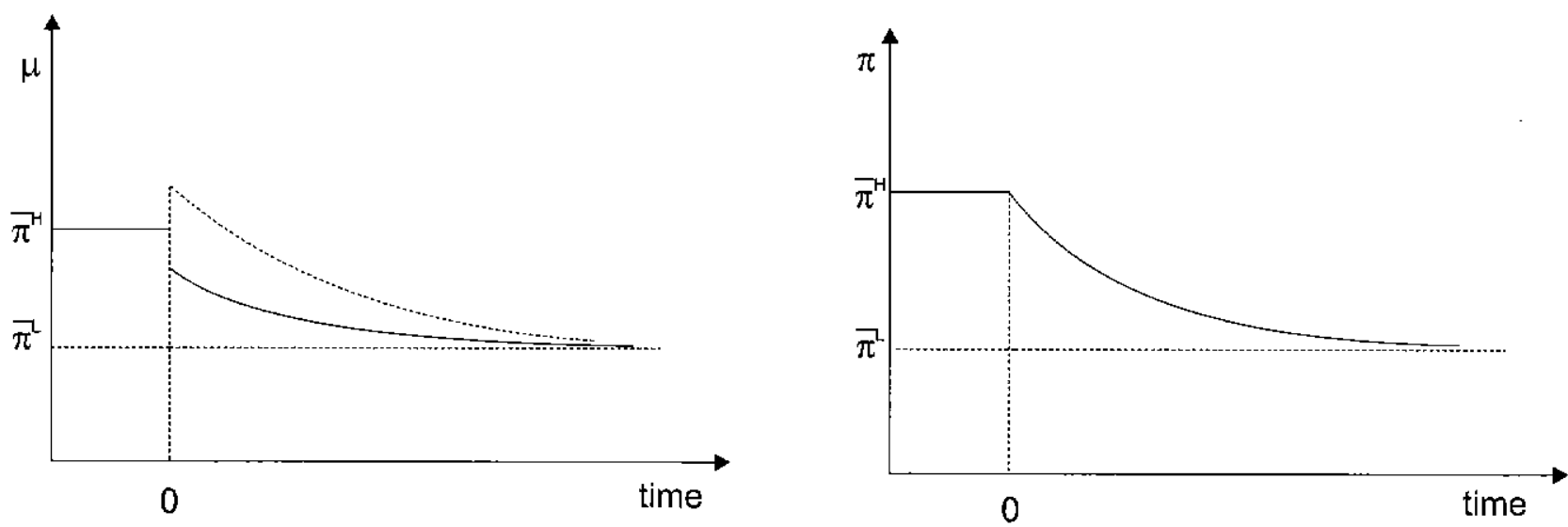

C. Real money balances

D. Consumption
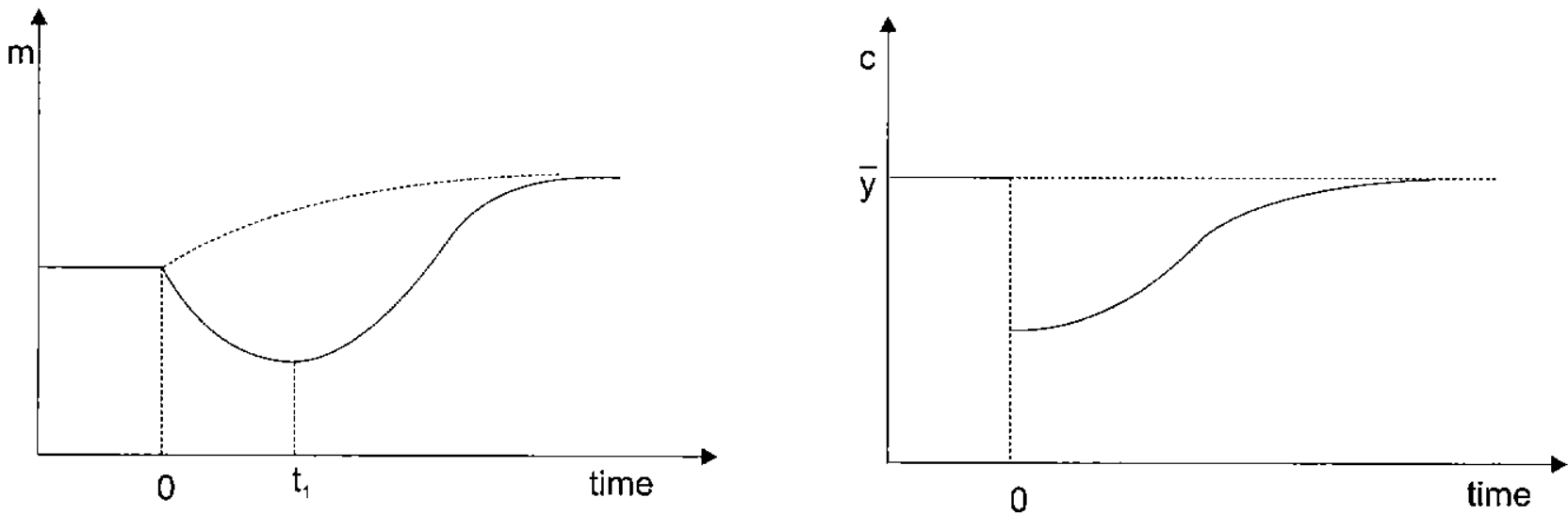

E. Nominal interest rate

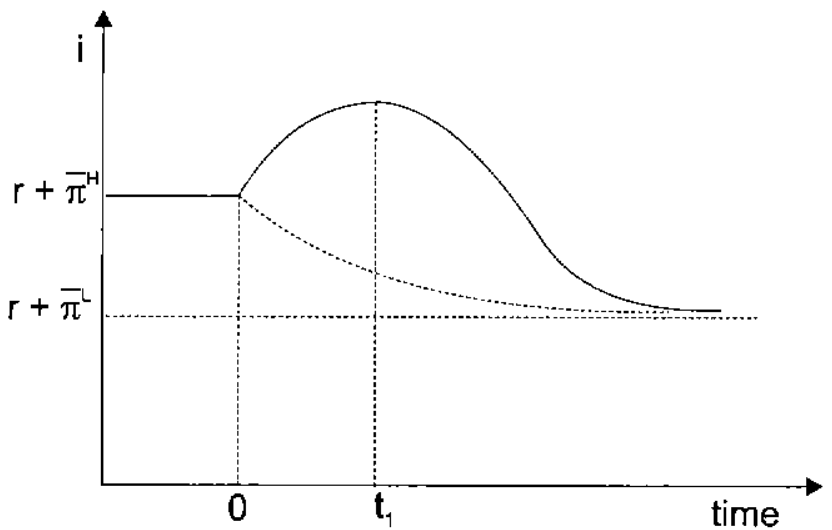

F. Real interest rate

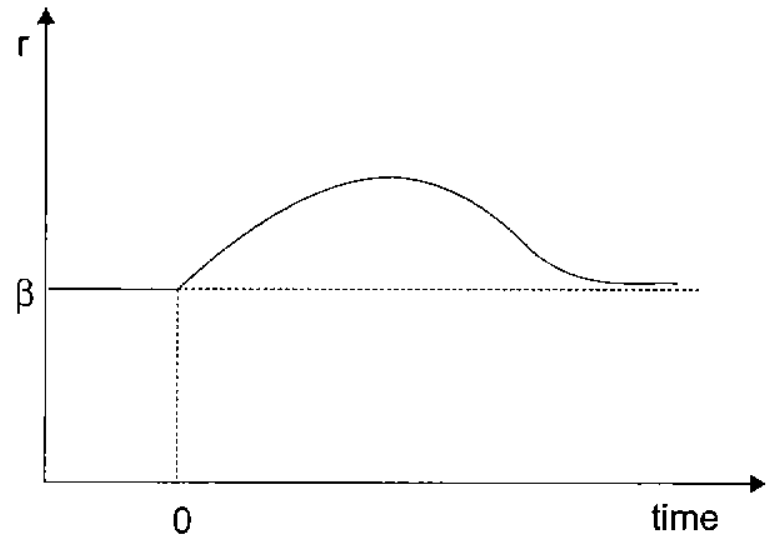

